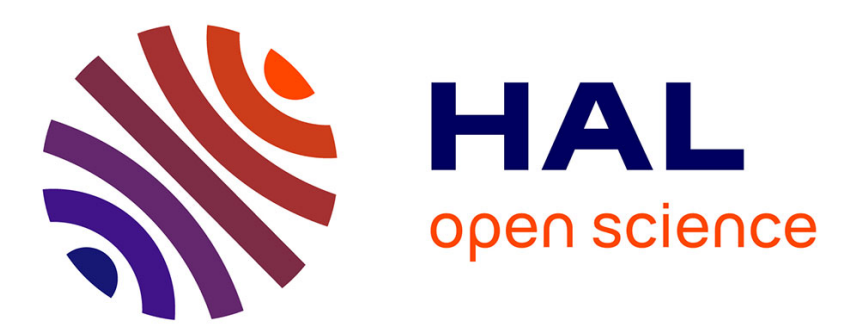

\title{
Regulation of mammalian cell cycle progression in the regenerating liver.
}

Anuradha Chauhan, Stephan Lorenzen, Hanspeter Herzel, Samuel Bernard

\section{To cite this version:}

Anuradha Chauhan, Stephan Lorenzen, Hanspeter Herzel, Samuel Bernard. Regulation of mammalian cell cycle progression in the regenerating liver.. Journal of Theoretical Biology, 2011, 283 (1), pp.10312. $10.1016 / j . j t b i .2011 .05 .026$. hal-00649211

\section{HAL Id: hal-00649211 https://hal.science/hal-00649211}

Submitted on 14 Jan 2020

HAL is a multi-disciplinary open access archive for the deposit and dissemination of scientific research documents, whether they are published or not. The documents may come from teaching and research institutions in France or abroad, or from public or private research centers.
L'archive ouverte pluridisciplinaire HAL, est destinée au dépôt et à la diffusion de documents scientifiques de niveau recherche, publiés ou non, émanant des établissements d'enseignement et de recherche français ou étrangers, des laboratoires publics ou privés. 


\title{
Regulation of cell cycle progression by Cdh1: Insight from an integrated mammalian cell cycle model
}

\author{
Anuradha Chauhan ${ }^{\mathrm{a}}$ Stephan Lorenzen ${ }^{\mathrm{c}}$ Hanspeter Herzel ${ }^{\mathrm{a}}$ \\ Samuel Bernard ${ }^{\mathrm{b}, *}$ \\ ${ }^{a}$ Institute for Theoretical Biology, Humboldt University, Invalidenstrasse 43, 10115 \\ Berlin, Germany \\ ${ }^{\mathrm{b}}$ Institut Camille Jordan, CNRS UMR5208, Université de Lyon, Université Lyon \\ 1, 43, boulevard du 11 novembre 1918, F-69622 Villeurbanne Cedex, France \\ ${ }^{\mathrm{c}}$ AG Systems Biology, Charité Center for Cardiovascular Research, Hessische \\ Strasse 3-4, 10115 Berlin, Germany
}

\begin{abstract}
The process of cell division in mammalian cells is orchestrated by cell-cycle-dependent oscillations of the cyclin protein levels. Cyclin levels are controlled by redundant transcriptional, post-translational and degradation feedback loops. How each of these separate loops contributes to the regulation of the key cell cycle events and to the connection between the G1-S transition and the subsequent mitotic events is under investigation. Cdc20 homologue 1 (Cdh1), well-known for controlling G1 phase progression, is emerging as an important regulator of DNA synthesis and mitosis. Here, we present an integrated computational model of the mammalian cell cycle based on the sequential activation of cyclins. We dissect the emergent role of Cdh1 as a universal regulator of the cell cycle. We validate the model against experimental data on liver cells (hepatocytes) during liver regeneration, which undergo one or two rounds of synchronous circadian-clock gated cell divisions. Our model is coherent with the notion that the mitotic exit in mammalian cells is bistable and suggests Cdh1 as a key regulator of mitosis. We suggest that Cdh1 plays an important role in controlling cell cycle events during G2 and mitosis phases.
\end{abstract}

Key words: Liver regeneration, mitosis, G1-S transition, G2 delay, Cdh1, Cyclin E

* Corresponding author. Tel.: +33472448317.

Email address: bernard@math.univ-lyon1.fr (Samuel Bernard). 


\section{Introduction}

The cell division cycle is a highly organized and structured mechanism in mammals. Because of its dynamical nature, it has been subject to several computational models. First computational models pertained to the cell cycle in amphibian embryos and yeast (Tyson, 1991; Goldbeter, 1991; Novak and Tyson, 1993; Sha et al., 2003; Pomerening et al., 2003; Chen et al., 2004). More recently, computational models were proposed for specific parts of the mammalian cell cycle, particularly the G1/S phase transition and the restriction point (Aguda and Tang, 1999; Qu et al., 2003a,b; Swat et al., 2004; Novak and Tyson, 2004). A generic model for the eukaryotic cell cycle has also been presented (Csikasz-Nagy et al., 2006).

Few detailed, integrative models coupling the main events of the cell cycle, DNA synthesis and mitosis have been proposed. Models of this sort have been proposed for yeast, in which growth of cell mass is playing a key role in regulating mitosis (Chen et al., 2004), and more recently for mammals (Gerard and Goldbeter, 2009). In mammals, however, cell mass is not a major determining factor for the control of cell cycle. Rather, mammalian cells possess multiple control mechanisms that prevent them from proliferating outside specific conditions. Mammalian cells vary in type and degree of differentiation, each one having different proliferative potential and mechanism. This makes the task of modelling mammalian cells challenging, as there is no universal experimental model. In vitro systems of dividing cells provide a way to study synchronized cell populations, which are suitable for modelling cell cycle events. However, cell cycle specific events are obtained under variable experimental conditions and different cell cycle synchronization procedures, which are difficult to reproduce on models. During liver regeneration, liver cells (hepatocytes) divide in a highly synchronized manner. We have taken advantage of the wealth of experimental data on the cell cycle during liver regeneration to construct the first integrative model of the mammalian cell cycle in the regenerating livers.

Liver regeneration is a process by which the liver can recover its normal mass and function following injury. After the surgical removal of two-third of the liver (partial hepatectomy), $90 \%$ of the hepatocytes re-enter the cell cycle synchronously to complete 1 or 2 divisions and restore the liver mass. Partial hepatectomy $(\mathrm{PH})$ triggers the release of pro-inflammatory cytokines (PIC). In the presence of PIC, hepatocytes leave a quiescent state, denoted G0, to enter a primed state, a process denoted priming. Primed cells, which are in the early G1 phase, are then driven by growth factors (GFs) to cross the restriction point, a point of no return beyond which they are irreversibly engaged in the cell cycle and do not require growth factors any more to complete mitosis (Taub, 2004). Progression within the cell cycle is controlled by the sequential activation of a family of cyclin dependent kinases (cdks) that allow an ordered 
succession of the cell cycle phases: G1, S, G2, and M (Morgan, 2007). The cdk proteins are only active when they form a complex with their corresponding cyclin proteins. Cyclin D/Cdk4-6, Cyclin E/Cdk2, Cyclin A/Cdk2, and Cyclin B/Cdk1 complexes promote, respectively, progression in G1 phase, the transition from G1 to $\mathrm{S}$ phase, progression in $\mathrm{S}$ and $\mathrm{G} 2$ phase, and finally the G2/M phase transition, allowing entry into mitosis (Morgan, 2007). Cyclin/cdk complexes are the workhorses of the cell cycle machinery, and as such, they need regulators. Cyclin/cdk regulation, which we henceforth mention as cyclin regulation for simplicity, is achieved through a variety of mechanisms. These include transcriptional regulation $[\mathrm{E} 2 \mathrm{~F}$ transcription factor 1 $(\mathrm{E} 2 \mathrm{~F})]$, association with protein inhibitors [cyclin dependent kinase inhibitor (CKI)], phosphorylation/dephosphorylation [Wee1 and cell division cycle 25 (Cdc25)] and cyclin degradation [complexes formed with anaphase promoting complex (APC) and Cdc20 homologue 1 (Cdh1) or Cell division cycle 20 $(\mathrm{Cdc} 20)\left(\mathrm{APC}^{C d h 1}, \mathrm{APC}^{C d c 20}\right)$, Skp1/cullin/F-box protein related complexes (SCF)] (Morgan, 2007) (Fig. 1).

\section{The model}

DNA synthesis and mitosis. After both $\mathrm{PH}$ and $\mathrm{CCl}_{4}$ treatment, liver regeneration exhibits well-synchronized DNA synthesis and mitosis (Deguchi et al., 2002). The temporal proliferation pattern of the cells in regenerating rodent livers consists of two waves of mitosis (Fabrikant, 1968). During the first round, hepatocytes synchronously undergo DNA replication and mitosis. It is then followed by a second round of division of less synchrony (Faktor, 1971). In mice, the first peak of DNA synthesis occurs 36 hours after $\mathrm{PH}$ and the mitotic peak, 4-12 hours after the peak of DNA synthesis (Matsuo et al., 2003).

E2Fs regulating sequential activation of cyclins. E2F activity is tightly controlled by binding to the retinoblastoma protein (Rb). Rb sequesters E2F and inhibits its transcriptional activity. Cyclins sequentially phosphorylate $\mathrm{Rb}$ and activate E2F in a positive feedback loop manner. Only hyperphosphorylated forms of Rb-E2F transactivates Cyclin A and Cyclin B (Lundberg and Weinberg, 1998) (see Appendix A.2 for the derivation of the Rb/E2F equations).

CKI at the interphase of S phase and mitosis. CKI stoichiometrically inhibits Cyclin D, Cyclin E and Cyclin A by forming complexes with their cdk partners (Harper et al., 1995). CKIs are predominantly transcriptionally 
regulated by cytokine-dependent signaling (Gartel and Tyner, 1999; Coller et al., 2000). For further details on modelling CKI activation refer to (Chauhan et al., 2008). Degradation of CKI is mediated by SCF and APC-Cdc20 (Bashir et al., 2004; Amador et al., 2007). For simplicity, we do not model SCF and/or APC-Cdc20 dependent degradation of CKI, but use a general degradation term for CKI.

Cyclins. The whole process of cell division is orchestrated by the sequential activation of cyclins. Cyclin D and Cyclin E are the G1-S cyclins that trigger DNA synthesis. G1-S cyclins are induced by cytokine- and growth factordependent pathways and their degradation is controlled by SCF. For further details on Cyclin D and Cyclin E modelling refer to (Chauhan et al., 2008). The rise of G1-S cyclins is accompanied by the appearance of Cyclin A during $\mathrm{S}$ phase. In the late G2 phase, a transient activation of Cyclin B is observed enabling swift G2-M transition. This transient activation is enabled by regulatory feedbacks imposed on Cyclin B by Cdc25 and Wee1. At metaphase, sufficiently high levels of active Cyclin B phosphorylates Cdc20 to form an active complex with APC, which in turn, degrades Cyclin B. Inactivation of Cyclin B allows mitotic exit and return to the G1 phase (Morgan, 2007). Inactivation of Cyclin B also leads to dephosphorylated Cdh1 which then forms an active complex with APC to degrade Cyclin B and Cyclin A during G1 phase.

APC and SCF: the degradators controlling the cell cycle APC is a proteasomal degradation machinery that needs to form complexes with subunits to be activated. During the cell cycle, APC is successively activated by two of its subunits, Cdc20 and Cdh1, which have separate windows of activity, each regulated by feedback loops. Cdc20 is activated by Cyclin B during mitosis through a negative feedback loop. Cdh1 becomes active at the end of mitosis through a positive feedback loop, when Cyclin B is degraded, and assembles with APC to further degrade Cyclin A, Cyclin B, Cdc20 and SCF (Wasch et al., 2010). Cdh1 also acts as a G1 regulator by destroying mitotic cyclins during G1 phase and maintaining the cell in G1 by the destruction of SCF (Bashir et al., 2004; Wei et al., 2004). Cdh1 controls Cyclin A and B at two levels: first by a direct cyclin-Cdh1 double feedback loop and second by a CyclinB-Cdc20 negative feedback. Cdh1 controls G1 cyclins, Cyclin D and E by degrading their degradator SCF.

SCF can degrade G1-S cyclins, Cyclin D and Cyclin E (Yu et al., 1998; Nakayama and Nakayama, 2005). SCF is down-regulated during M and G1 phases and is induced by Cyclin $\mathrm{E}$ near the $\mathrm{S}$ phase when its degradator Cdh1 is degraded (Bashir et al., 2004). Cdh1 connects the SCF-driven G1-S proteolytic machinery with the APC-dependent mitotic and G1 proteolysis. 
Therefore, at the core of the cell cycle lies Cdh1-driven degradation that results in a proteolytic oscillator setting the pace of the cell cycle progression.

Using the existing knowledge about cyclin control mechanisms and their temporal organization during liver regeneration, we designed the network controlling the cyclin-dependent kinase activity at all stages of the cell cycle (Fig. 1). The model is a system of ordinary differential and algebraic equations describing the concentration of key players of the cell cycle (See Appendix A for a description of the model variables). To make the model as tractable as possible, the variables were sorted according to the time scale on which they evolve. The time-scale of reference is the duration of one cell cycle (in hours). Variables that change on a shorter time-scale were approximated by their steady state (quasi-steady state assumption). For instance, concentrations of phosphorylated proteins were approximated by their steady states. To limit the number of variables in the model, we considered explicitly protein concentrations but not their corresponding mRNA concentrations. The kinetic parameters (see Appendix B) were adjusted so that the model could represent the experimentally observed temporal dynamics of respective model species. The induction of gene expression by pro-inflammatory cytokines, growth factors and by Rb-E2F (here called E2F) was incorporated directly by time-dependent input functions modulating the synthesis of cyclins (see (Chauhan et al., 2008) and Appendix A.2). Post-translational regulation through phosphorylationdephosphorylation or through complex formation is explicitly included in the model. For simplicity, we do not distinguish between the nuclear and cytosolic compartments of the cell. The model describes the dynamics of the intracellular cyclin/cdk network and represents an average hepatocyte during liver regeneration. Our aim is to address one cycle of division during liver regeneration triggered by a decaying damage (Hayashi et al., 2003; Blindenbacher et al., 2003). All concentrations in the model are expressed in arbitrary units (a.u.) since for most of the regulatory proteins, the actual concentrations are not known.

Numerical simulations of the full model were performed with Matlab. Bistability analysis of the model was done with the numerical bifurcation continuation process of XPPAUT.

\section{Results}

\subsection{Sequential activation of cyclins and proteolytic degradators}

The computational model is able to reproduce the sequential activation of cyclins and proteolytic degradators along the cell cycle (Fig. 2). Damage ac- 
tivates cytokine- and growth factor-induced pathways which lead to the activation of Cyclin D during late G1 and the subsequent activation of Cyclin E, indicating entry into S phase (Chauhan et al., 2008). Step-wise activation of E2F via Cyclin D and Cyclin E leads to the sequential transcription of Cyclin $\mathrm{A}$ in the $\mathrm{S}$ phase and Cyclin B during mitosis (Morgan, 2007) (for equations see Appendix A.2). CKI is activated in early G1 and is maximally elevated at late S phase (Behrens et al., 2002). E2F activity peaks at S phase (Chen et al., 2009). APC ${ }^{C d h 1}$ is active during late mitosis and early G1 phase, degrading Cyclin A and Cyclin B. $\mathrm{APC}^{C d c 20}$, which is a degradator of mitotic substrates, is activated during late mitosis, once Cyclin B is sufficiently activated. Degradator of G1-S cyclins, SCF, becomes active at the end of S phase, leading to the degradation of Cyclin $\mathrm{D}$ and Cyclin $\mathrm{E}$. Also, mitotic regulators Cyclin B active, Wee1, Cdc25 and $\mathrm{APC}^{C d c 20}$ exhibit a delayed switch-like activation (Morgan, 2007) (Fig. 2).

\subsection{A switch in Cyclin $B$ activity drives $M$ phase progression}

A switch-like increase in the activity of Cyclin B enables entry into mitosis, whereas subsequent Cyclin B proteolysis promotes exit from mitosis (Morgan, 2007). This switch-like behavior is made possible by the presence of controls on Cyclin B activation, which conserves the total amount of Cyclin B, and on total Cyclin B concentration.

Two feedback loops control Cyclin B activity: a double negative feedback loop from the inhibitory kinase Wee1, which is itself inhibited by Cyclin B, and a positive feedback loop from the activating phosphatase Cdc25, which is further activated by Cyclin B (Tyson et al., 2003). Recently, Potapova et al. (2009) have shown that the exit from mitosis was also a switch phenomenon, due to the Wee1 and Cdc25-dependent positive feedback loops acting during G1 phase.

Total Cyclin B concentration is controlled through synthesis, by E2F, and degradation, by $\mathrm{APC}^{C d h 1}$ and $\mathrm{APC}^{C d c 20}$. E2F promotes Cyclin B synthesis. At low E2F activity, there is not enough Cyclin B for any of it to be activated. If E2F reaches a threshold value, Cyclin B gets activated. This threshold activation is achieved through a transcritical bifurcation (Fig. 3 (a)) (Guckenheimer and Holmes, 1997). At any E2F values, two steady states for Cyclin B exist, one zero and one either negative (below the threshold) or positive (above the threshold). The zero steady state is stable below the threshold and the positive steady state is stable above it. This transcritical bifurcation is possible because of the Cdc25 loop. When this loop is switched off by setting Cdc25 to a low constant level (set at 0.01), the transcritical bifurcation disappears. No effect was observed when Wee1 loop was removed (results not shown). $\mathrm{APC}^{C d h 1}$ is 
responsible for the activation of Cyclin B by a double negative feedback loop regulation, while $\mathrm{APC}^{C d c 20}$ is mainly responsible for its degradation at the exit of mitosis. Varying the strength of the degradation rate $\mathrm{d}_{C B}^{C d h 1}$ revealed a bistable switch that allows rapid activation and inactivation of Cyclin B (Fig. 3 (b)). At high degradation rate, there is a small total amount of Cyclin $\mathrm{B}$, and no active Cyclin $\mathrm{B}$. When the degradation rate is reduced, a second stable steady state appears through a saddle-node bifurcation. These two stable steady states co-exist until the low level steady state becomes unstable, through a reverse pitchfork bifurcation (Guckenheimer and Holmes, 1997). For degradation rates below that level, there is only high Cyclin B activity. This combination of bifurcations form a bistable switch whereby low and high levels of Cyclin B are possible.

Thus, our model includes two mechanisms for controlling Cyclin B activity: a transcritical activation by $\mathrm{E} 2 \mathrm{~F}$ and a bistable switch induced by $\mathrm{APC}^{C d h 1}$ mediated Cyclin B degradation. The transcritical activation ensures active Cyclin B levels remain to zero whenever total Cyclin B level are low, therefore preventing accidental entry into mitosis. The bistable switch is responsible for the rapid activation of Cyclin B at the entry to mitosis, and its rapid elimination at the end of mitosis.

\subsection{Liver regeneration and cell cycle progression are robust processes}

Liver regeneration is a robust process. After $\mathrm{PH}$, the liver grows back to its normal mass even in the absence of important cell cycle players. Therefore we expect Cyclin E and Cyclin B activity, as a measure of total DNA synthesis and mitosis respectively, to be robustly activated. We analysed the sensitivity of Cyclin E and Cyclin B activity with respect to changes in biochemical parameters. Both Cyclin E and Cyclin B were robust to parameter change except when parameters immediately downstream of the damage, such as degradation of PIC, were varied. In case of these sensitive parameters, Cyclin E and Cyclin B peaks showed a bell-shaped response to systematic variation in these sensitive parameters (results now shown).

We further went on to study the response of the model to systematic changes in the damage. We varied the damage from strong-transient to weak-sustained input keeping the the total amount of damage, i.e. the integral under the curve, constant. Both DNA synthesis (Cyclin E) and mitosis (Cyclin B) responded as a bandpass filter to such a systematic variation in damage (Fig. 4a-b, upper panels). Weak-sustained and strong-transient damages were rejected and the cells did not progress through both DNA synthesis and mitosis in both cases. The timing of cell cycle events was robust to varying nature of damage (Fig. 4ab, lower panels). 
Bandpass filtering properties have been studied previously in a G1/S model (Chauhan et al., 2008). The damage was transmitted through two pathways: 1) direct ultrasensitive induction of Cyclin E, which filtered out the weaksustained damages; and 2) Cytokine mediated delayed pathway, which consisted of nested feedforward loops. Incoherent feedforward loops via CKI and HGF filtered out sharp-transient damages. In the present model, changing the strength of feedback loops during G2/M/G1 phases did not change bandpass filtering behaviour of the model. However, the range of the bandpass filter was affected. Decreasing the positive feedback loop strength of the Cdh1-Cyclin A loop by reducing the two Cyclin A and Cdh1 mutual negative regulation parameters to one-half, one-fourth and zero respectively, had two distinct filtering effects: it decreased the range of the filter in case of Cyclin B, while for Cyclin E, it increased the range of filter (Fig. 5). This opposing control of cell cycle events: DNA synthesis (Cyclin E) and mitosis (Cyclin B) with respect to varying damage, has not been systematically studied to our knowledge.

\subsection{The circadian clock gates mitosis but not DNA synthesis}

Cell division in many mammalian tissues is associated with the circadian clock, a $\sim 24$ h rhythm regulating physiology and behaviour (Reppert and Weaver, 2002). In hepatocytes, Wee1 is the gatekeeper of this circadian control of cell cycle (Matsuo et al., 2003). Wee1 is a clock-controlled gene (its expression is modulated over $24 \mathrm{~h}$ ), and regulates the timing and efficiency of the cell cycle. In mice hepatocytes, Wee1 synthesis peaks around ZT12 (ZT0 represents lights on and ZT12, lights off, in a $24 \mathrm{~h}$ light-dark cycle) (Matsuo et al., 2003). To simulate the circadian expression of Wee1, we used a sinusoidalshaped synthesis rate of Wee1, with a maximal synthesis rate at ZT12 (See Appendix A.6). We simulated PHs performed on mice at ZT8 or ZT0, and used peak of activity in Cyclin B and E as markers of mitosis and S phase. We found that mitotic activity induced by Cyclin B at ZT8 or ZT0 changes from 44.5 to 51.5 hours (Fig. 6). These results reproduce well the gating properties of Wee1 observed experimentally (Matsuo et al., 2003).

In our model, DNA synthesis is directly coupled to mitosis via a Cdh1-SCF loop. Nevertheless, Cyclin E activity, which is representative of DNA replication, was independent from Zeitgeber time PH (Fig. 6). Imposition of circadian control on Wee1 maintains DNA synthesis as an independently controlled property of hepatocytes (Matsuo et al., 2003). 


\subsection{HGF treatment at $S$ phase causes G2 delay}

Growth factors are well known to promote the transition from G1 to S phase in cell cycle progression. Beyond G1-S transition, however, growth factors have been considered non-essential for the progression of the cell cycle (Jones and Kazlauskas, 2001). Yet, when injected at S phase, hepatocyte growth factor induces a G2 delay (Park et al., 2007). This delay is marked by a delayed degradation of Cyclin A and Cyclin B, resulting in a delayed mitotic entry. It is not very intuitive how HGF induction at $\mathrm{S}$ phase might lead to delayed degradation of Cyclin A and Cyclin B. CKI up-regulation has been implicated in this delay (Park et al., 2007). We simulated growth factor induction at S phase by giving an extra HGF pulse during $\mathrm{S}$ phase between 36 and 40 hours (See Appendix A.7). Our model was able to reproduce the observed delay in the degradation of Cyclin A and Cyclin B representing a G2 delay (Fig. 7 (e-f)). Our simulations suggest that HGF treatment at S phase delays $\mathrm{APC}^{C d h 1}$ up-regulation and prolongs E2F activation. Thus, HGF induction at $\mathrm{S}$ phase might also prolong E2F mediated mitotic transcription and hence Cyclin A activation. As long as Cyclin A is active at G2, APC ${ }^{C d h 1}$ can not be activated due to its antagonistic control by Cyclin A. This leads to delayed Cdh1 activation. Delayed Cdh1 activation leads to delayed degradation of Cyclin A and Cyclin B (Fig. 7 (b-d)).

\section{Discussion}

\section{Computational Model for Mammalian Cell Cycle}

We have developed a computational model for the cell cycle of hepatocytes during liver regeneration that couples different cyclins and proteolytic degradators in a sequential manner. We introduced Cdh1 as a universal controller of the cell cycle. Recent experimental data have identified Cdh1 as a major controller of cell cycle progression.

The model recapitulates the temporal profile of dividing hepatocytes following partial hepatectomy: the sequential activation of cyclins and proteolytic degradators; the effect of the circadian clock on the timing of mitosis; the G2 phase delay caused by HGF treatment during $S$ phase and the effect of Cdh1 on cell cycle progression.

Gerard and Goldbeter (2009) recently presented a mammalian cell cycle model describing the sequential cyclin-cdk activation. The model demonstrates repetitive cell cycling in the presence of suprathreshold amounts of growth factors. The emphasis was on the Rb-E2F network during G1 phase and Cyclin A- 
dependent activation of Cyclin B during mitotic entry. Our model is also structurally able to generate sustained oscillations like many other cell cycle models (Csikasz-Nagy et al., 2006; Gerard and Goldbeter, 2009). However, the focus of the model presented here is to simulate one or two cycles of cell division observed during injury induced liver regeneration, and on the emerging role of Cdh1 in regulating the cell cycle.

\section{Threshold activation of Cyclin B}

Entry to and exit from M phase display a switch-like behaviour in Cyclin B levels. It is rapidly switched on at the G2-M phase transition and rapidly switched off at the end of mitosis. Threshold activation provides a robust mechanism for switch. We have shown that total Cyclin B concentration and activity is regulated by two threshold processes: a transcritical bifurcation, mediated by $\mathrm{E} 2 \mathrm{~F}$ and a bistable loop, mediated by $\mathrm{APC}^{C d h 1}$. Both the transcritical bifurcation and the bistable loop allowed active Cyclin B to be kept at zero levels outside the specific time window of activity during G2/M phases. Although transcritical activation is qualitatively different from a bistable switch, it also provides a sharp activation threshold.

\section{Bandpass Filter of Damage Input}

The model exhibits bandpass filter properties which allows the system to ignore strong-transient and weak-sustained damages, as already discussed (Chauhan et al., 2008). Thus, if the damage is too strong and transient or too weak, cells will not enter the cell cycle events of DNA synthesis and mitosis. This is in agreement with observations that liver regeneration is proportional to the amount of $\mathrm{PH}$ but does not occur if the $\mathrm{PH}$ is too small or too large (Lambotte et al., 1997). Also, varying the feedback strength of Cdh1-Cyclin A positive feedback loop in the model tunes the range of filtering for Cyclin $\mathrm{E}$ and $\mathrm{Cy}-$ clin B in an opposing manner. Such an opposite control of DNA synthesis and mitosis with varying feedback strength of Cdh1-Cyclin A positive feedback has not been systematically studied to our knowledge. Opposite control of filtering range for Cyclin E and Cyclin B can have some interesting physiological implications. Certain environmental conditions promote DNA synthesis while suppress mitosis during endoreplication and polyploidization (Nevzorova et al., 2009). Cdh1-mediated control of cyclins during endoreplication has been widely reported in mammals, Drosophila and plants (Garcia-Higuera et al., 2008; Sigrist and Lehner, 1997; Sorensen et al., 2000; Kasili et al., 2010). It would be interesting to study Cdh1-mediated feedback loop control of cell cycle with respect to endoreplication and polyploidisation, which are common forms of cell cycle progression during liver regeneration (Duncan et al., 2010).

\section{Circadian control of Wee1}

Our model is consistent with a circadian control of Wee1 synthesis, affecting 
the timing of mitosis but not of DNA synthesis. When the entrainment to light-dark cycle is simulated by varying Wee1 synthesis with a $24 \mathrm{~h}$ period, the time at which $\mathrm{PH}$ is performed has a impact on the timing of mitosis. In agreement with Matsuo et al (2003) results, we found that in $\mathrm{PH}$ performed at ZT0 and ZT8 (at lights on and 8 hours later respectively), cells enter mitosis roughly at the same time (around $60 \mathrm{~h}$ after ZT0). This shows that circadian regulation of Wee1 induces a gating process by which cells cannot divide at any time of the day. The timing of DNA synthesis was independent from the timing of $\mathrm{PH}$, and occurred 36 hours after $\mathrm{PH}$, coherent with experimental results. In hepatocytes, Wee1 is a major link between the circadian clock and the cell cycle and $\mathrm{S}$ phase is largely a circadian clock-independent process, despite the presence of a feedback loop linking G1/S and G2/M phases via Cdh1 and SCF. In continuously dividing cells this independence might not be preserved as gating mitosis might affect subsequent phases.

\section{HGF treatments during $S$ phase causes G2 delay}

HGF accelerates cell cycle progression but has been mostly assumed to be nonessential beyond G1-S transition. However, HGF injection at S phase leads to a G2 delay resulting in delayed degradation of cyclins during G2-M phase. The model was able to reproduce a G2 phase delay caused by growth factor treatment during $\mathrm{S}$ phase marked with delayed degradation of Cyclin A and Cyclin B. Erk signaling is known to mediate this G2 delay via CKI (Han et al., 2005; Dangi et al., 2006; Park et al., 2007). Our simulations suggest that CKI, $\mathrm{APC}^{C d h 1}$ and $\mathrm{E} 2 \mathrm{~F}$ contribute in delaying the degradation of Cyclin A and Cyclin B. This leads us to the conclusion that induction of growth factors during $\mathrm{S}$ phase might lead to prolonged transcriptional activity of E2F resulting in increased Cyclin A activity. Since the antagonistic Cyclin A and $\mathrm{APC}^{C d h 1}$ can not coexist, $\mathrm{APC}^{C d h 1}$ is delayed. Thus the $\mathrm{APC}^{C d h 1}$-dependent degradation machinery might be responsible for the delayed Cyclin A and Cyclin B degradation during G2 phase delay. Therefore, our model shows that $\mathrm{APC}^{C d h 1}$ might have a crucial role to play during G2 delay.

\section{Conclusion}

Mounting evidences demonstrate that Cdh1 plays a central role in the control of proliferation, differentiation and maintenance of genomic integrity by timely and coordinated degradation of several substrates (Wasch et al., 2010). Cdh1 maintains the stability of G1 phase by degrading the degradator of G1$\mathrm{S}$ cyclins and SCF. Cdh1 is also required for G2 DNA-damage checkpoint by controlling the degradation of Cyclin A and Cyclin B (Wasch et al., 2010). Cdh1 is also being implicated in genomic instability and cancers and is under investigation as a therapeutic target. Recent developments call for a better characterization of the role of Cdh1 in the control of G2 phase. It will be interesting to dissect a Cdh1 based cell cycle model in order to understand the 
G2 delay and might help in better understanding of the fate of mitosis.

Also, owing to the role of Cdh1 in specialised cell division cycles of endoreplication and polyploidy, widely observed during liver regeneration, a Cdh1 centered cell cycle model would be suitable to understand underlying mechanisms controlling the causes and consequences of such specialised cell cycle events.

\section{Acknowledgements}

AC was supported by the German Ministry Federal Ministry of Education and Research (BMBF, Hepatosys, 0313078A) and by SFB 618 grant of the Deutsche Forschungsgesellschaft (DFG). SL was supported by the German Ministry Federal Ministry of Education and Research (BMBF, Hepatosys, 0313078A). SB was supported by the Project-Team INRIA Dracula (France), the French National Research Agency (ProCell, ANR-09-JCJC-0100-01), and acknowledges support from RhôneAlpes Complex Systems Institute (IXXI, France). We thank two anonymous reviewers for their useful suggestions. 


\section{References}

Aguda, B. D. and Tang, Y. (1999), Cell Prolif 32(5), 321

Amador, V., Ge, S., Santamaria, P. G., Guardavaccaro, D., and Pagano, M. (2007) , Mol Cell 27(3), 462

Bashir, T., Dorrello, N. V., Amador, V., Guardavaccaro, D., and Pagano, M. (2004), Nature 428(6979), 190

Behrens, A., Sibilia, M., David, J.-P., Möhle-Steinlein, U., Tronche, F., Schütz, G., and Wagner, E. F. (2002) , EMBO J 21(7), 1782, c-jun cyclineD

Blindenbacher, A., Wang, X., Langer, I., Savino, R., Terracciano, L., and Heim, M. H. (2003), Hepatology 38(3), 674

Chauhan, A., Legewie, S., Westermark, P. O., Lorenzen, S., and Herzel, H. (2008) , J Theor Biol 252(3), 465

Chen, H.-Z., Tsai, S.-Y., and Leone, G. (2009) , Nat Rev Cancer 9(11), 785

Chen, K. C., Calzone, L., Csikasz-Nagy, A., Cross, F. R., Novak, B., and Tyson, J. J. (2004), Mol Biol Cell 15(8), 3841

Coller, H. A., Grandori, C., Tamayo, P., Colbert, T., Lander, E. S., Eisenman, R. N., and Golub, T. R. (2000), Proc Natl Acad Sci U S A 97(7), 3260

Csikasz-Nagy, A., Battogtokh, D., Chen, K. C., Novak, B., and Tyson, J. J. (2006) , Biophys J 90(12), 4361

Dangi, S., Chen, F. M., and Shapiro, P. (2006) , Cell Prolif 39(4), 261

Deguchi, M., Shiraki, K., Inoue, H., Okano, H., Ito, T., Yamanaka, T., Sugimoto, K., Sakai, T., Ohmori, S., Murata, K., Furusaka, A., Hisatomi, H., and Nakano, T. (2002), Biochem Biophys Res Commun 297(1), 59

Duncan, A. W., Taylor, M. H., Hickey, R. D., Hanlon Newell, A. E., Lenzi, M. L., Olson, S. B., Finegold, M. J., and Grompe, M. (2010) , Nature 467(7316), 707

Fabrikant, J. I. (1968) , J Cell Biol 36(3), 551

Faktor, V. M. (1971), Biull Eksp Biol Med 72(9), 97

Garcia-Higuera, I., Manchado, E., Dubus, P., Canamero, M., Mendez, J., Moreno, S., and Malumbres, M. (2008), Nat Cell Biol 10(7), 802

Gartel, A. L. and Tyner, A. L. (1999), Exp Cell Res 246(2), 280

Gerard, C. and Goldbeter, A. (2009), Proc Natl Acad Sci U S A 106(51), 21643

Goldbeter, A. (1991), Proc Natl Acad Sci U S A 88(20), 9107

Guckenheimer, J. and Holmes, P. (1997) , Nonlinear oscillations, dynamical systems, and bifurcations of vector fields, Vol. v. 42 of Applied mathematical sciences, New York: Springer, corr. 5th print edition

Han, J., Tsukada, Y.-i., Hara, E., Kitamura, N., and Tanaka, T. (2005) , J Biol Chem 280(36), 31548

Harper, J. W., Elledge, S. J., Keyomarsi, K., Dynlacht, B., Tsai, L. H., Zhang, P., Dobrowolski, S., Bai, C., Connell-Crowley, L., and Swindell, E. (1995), Mol Biol Cell 6(4), 387

Hayashi, E., Yasui, A., Oda, K., Nagino, M., Nimura, Y., Nakanishi, M., Motoyama, N., Ikeda, K., and Matsuura, A. (2003) , J Surg Res 111(2), 196 
Jones, S. M. and Kazlauskas, A. (2001) , FEBS Lett 490(3), 110

Kasili, R., Walker, J. D., Simmons, L. A., Zhou, J., De Veylder, L., and Larkin, J. C. (2010), Genetics 185(1), 257

Lambotte, L., Saliez, A., Triest, S., Tagliaferri, E. M., Barker, A. P., and Baranski, A. G. (1997), Am J Physiol 273(4 Pt 1), G905

Lundberg, A. S. and Weinberg, R. A. (1998), Mol Cell Biol 18(2), 753

Matsuo, T., Yamaguchi, S., Mitsui, S., Emi, A., Shimoda, F., and Okamura, H. (2003), Science 302(5643), 255

Morgan, D. O. (2007), The cell cycle: principles of control, London: Published by New Science Press in association with Oxford University Press

Nakayama, K. I. and Nakayama, K. (2005) , Semin Cell Dev Biol 16(3), 323

Nevzorova, Y. A., Tschaharganeh, D., Gassler, N., Geng, Y., Weiskirchen, R., Sicinski, P., Trautwein, C., and Liedtke, C. (2009), Gastroenterology 137(2), 691

Novak, B. and Tyson, J. J. (1993) , J Cell Sci 106 ( Pt 4), 1153

Novak, B. and Tyson, J. J. (2004), J Theor Biol 230(4), 563

Park, Y. Y., Nam, H.-J., and Lee, J.-H. (2007) , Biochem Biophys Res Commun 356(1), 300

Pomerening, J. R., Kim, S. Y., and Ferrell, J. E. J. (2005), Cell 122(4), 565

Pomerening, J. R., Sontag, E. D., and Ferrell, J. E. J. (2003) , Nat Cell Biol $5(4), 346$

Potapova, T. A., Daum, J. R., Byrd, K. S., and Gorbsky, G. J. (2009) , Mol Biol Cell 20(6), 1737

Qu, Z., MacLellan, W. R., and Weiss, J. N. (2003a), Biophys J 85(6), 3600

Qu, Z., Weiss, J. N., and MacLellan, W. R. (2003b), Am J Physiol Cell Physiol 284(2), C349

Reppert, S. M. and Weaver, D. R. (2002), Nature 418(6901), 935

Sha, W., Moore, J., Chen, K., Lassaletta, A. D., Yi, C.-S., Tyson, J. J., and Sible, J. C. (2003), Proc Natl Acad Sci U S A 100(3), 975

Sigrist, S. J. and Lehner, C. F. (1997), Cell 90(4), 671

Sorensen, C. S., Lukas, C., Kramer, E. R., Peters, J. M., Bartek, J., and Lukas, J. (2000), Mol Cell Biol 20(20), 7613

Swat, M., Kel, A., and Herzel, H. (2004) , Bioinformatics 20(10), 1506

Taub, R. (2004), Nat Rev Mol Cell Biol 5(10), 836

Tyson, J. J. (1991), Proc Natl Acad Sci U S A 88(16), 7328

Tyson, J. J., Chen, K. C., and Novak, B. (2003) , Curr Opin Cell Biol 15(2), 221

Wasch, R., Robbins, J. A., and Cross, F. R. (2010), Oncogene 29(1), 1

Wei, W., Ayad, N. G., Wan, Y., Zhang, G.-J., Kirschner, M. W., and Kaelin, W. G. J. (2004), Nature 428(6979), 194

Yu, Z. K., Gervais, J. L., and Zhang, H. (1998) , Proc Natl Acad Sci U S A 95(19), 11324 


\section{Appendix}

\section{A Model equations}

The model contains 25 dynamical variables and 84 parameters. The 25 variables are the concentrations of the following players involved in the cell cycle control: Damage (D) induced pro-inflammatory cytokine pathways (PIC and PGE); proinflammatory cytokine induced growth factor pathways (PAI, HGF, HB-EGF); Cyclins D, E, A, and B; the inhibitor CKI and its complexes with the active cyclin-cdk complexes; the active and inactive forms of phosphatase Cdc25 and of kinase Wee1; the SCF proteasomal ligases involved in the degradation of cyclin D, Cyclin E and CKI; and the active and inactive forms of the proteins Cdh1 and Cdc20 involved in the degradation of cyclins $\mathrm{A}$ and $\mathrm{B}$

\section{A.1 G1-S model}

$$
\begin{aligned}
{[D] } & =I_{0} \cdot e^{-d_{0} \cdot t} \\
\frac{d[P I C]}{d t} & =\frac{v_{1}}{1+\left(\frac{[P G E]}{k_{1}^{-}}\right)^{2}} \cdot \frac{[D]}{k_{1}+[D]}-d_{1} \cdot[P I C] \\
\frac{d[P G E]}{d t} & =v_{2} \cdot[P I C]-d_{2} \cdot[P G E] \\
\frac{d[I E G]}{d t} & =\frac{v_{3} \cdot[P I C]^{3}}{k_{3}^{3}+[P I C]^{3}}-d_{3} \cdot[I E G] \\
\frac{d[P A I]}{d t} & =\frac{v_{4} \cdot[P I C]^{3}}{k_{4}^{3}+[P I C]^{3}}-d_{4} \cdot[P A I] \\
\frac{d[H G F]}{d t} & =\frac{v_{5} \cdot[I E G]}{1+\left(\frac{[P A I]}{k_{5}^{-}}\right)^{4}} \cdot\left(1+\frac{f_{5} \cdot[H G F]}{k_{5}+[H G F]}\right)-d_{5}[H G F] \\
\frac{d[H B E G F]}{d t} & =v_{6} \cdot \frac{[D]^{4}}{k_{61}^{4}+[D]^{4}} \cdot \frac{[I E G]}{k_{62}+[I E G]} \cdot \frac{[H G F]}{k_{63}+[H G F]} \\
& -d_{6}[H B E G F] \\
\frac{d[C K I]}{d t} & =v_{7} \cdot \frac{P I C}{k_{7}+P I C}-d_{7} \cdot[C K I] \\
& -\frac{d[C y c D \mid C K I]}{d t}-\frac{d[C y c E \mid C K I]}{d t}-\frac{d[C y c A \mid C K I]}{d t} \\
\frac{d[C y c D]}{d t} & =\frac{v_{8} \cdot[I E G] \cdot[H G F]}{k_{8}+[I E G]}+d_{10} \cdot[C y c D \mid C K I] \\
& -\left(d_{8} \cdot[S C F]+v_{10} \cdot[C K I]\right) \cdot[C y c D] \\
\frac{d[C y c E]}{d t} & =\frac{v_{91} \cdot[H B E G F]^{2}}{k_{91}^{2}+[H B E G F]^{2}}+\frac{v_{92} \cdot[C y c D]^{4}}{k_{92}^{4}+[C y c D]^{4}}+d_{11} \cdot[C y c E \mid C K I] \\
& =(\mathrm{A})
\end{aligned}
$$




$$
\begin{aligned}
& -\left(d_{9} \cdot[S C F]+v_{11} \cdot[C K I]\right) \cdot[C y c E] \\
\frac{d[C y c D \mid C K I]}{d t} & =v_{10}[C K I][C y c D]-d_{10}[C y c D \mid C K I] \\
\frac{d[C y c E \mid C K I]}{d t} & =v_{11}[C K I][C y c E]-d_{11}[C y c E \mid C K I] \\
\frac{d[S C F]}{d t} & =v_{12} \cdot C y c E-d_{122} \cdot S C F \cdot[A P C \mid C d h 1]-d_{12} \cdot S C F
\end{aligned}
$$

\section{A.2 E2F steady state}

$R b$ phosphorylation is initiated by Cyclin $\mathrm{D}$, releasing E2F in sufficient quantity for Cyclin $\mathrm{E}$ activation. Cyclin $\mathrm{E}$ further phosphorylates $\mathrm{Rb}\left(R b_{P}\right)$ resulting in hyperphosphorylated $R b_{p p}$, releasing higher amounts of E2F required for transcriptional activation of further Cyclins. Phosphorylation/dephsophorylation reactions of $\mathrm{Rb}$ and association/dissociation of its three phosphorylated forms with E2F are fast enough to be in the steady state equilibrium.

$$
\begin{aligned}
{\left[R b_{T}\right] } & =[R b]+\left[R b_{p}\right]+\left[R b_{p p}\right]+[R b \cdot E 2 F]+\left[R b_{p} \cdot E 2 F\right]+\left[R b_{p p} \cdot E 2 F\right] \\
{\left[E 2 F_{T}\right] } & =[E 2 F]+[R b \cdot E 2 F]+\left[R b_{p} \cdot E 2 F\right]+\left[R b_{p p} \cdot E 2 F\right] \\
{\left[R b_{p}\right] } & =p_{1} \cdot[R b] \cdot[C y c D] \\
{\left[R b_{p p}\right] } & =p_{1} p_{2} \cdot[R b] \cdot[C y c D] \cdot[C y c E] \\
{[R b \cdot E 2 F] } & =k_{1} \cdot[R b] \cdot[E 2 F] \\
{\left[R b_{p} \cdot E 2 F\right] } & =p_{1} k_{2} \cdot[R b] \cdot[C y c D] \cdot[E 2 F] \\
{\left[R b_{p p} \cdot E 2 F\right] } & =p_{1} p_{2} k_{3} \cdot[R b] \cdot[C y c D] \cdot[C y c E] \cdot[E 2 F]
\end{aligned}
$$

Substituting the steady state values, we solve the equation for E2F as

$$
\begin{aligned}
E 2 F & =-\frac{R b_{T}-E 2 F_{T}+C}{2}+\sqrt{\frac{\left(R b_{T}-E 2 F_{T}+C\right)^{2}}{4}+C}, \text { where } \\
C & =\frac{1+p_{1} \cdot[C y c D]+p_{1} p_{2} \cdot[C y c D] \cdot[C y c E]}{k_{1}+k_{2} p_{1} \cdot[C y c D]+k_{3} p_{1} p_{2} \cdot[C y c D] \cdot[C y c E]}
\end{aligned}
$$

\section{A.3 APC steady state}

$$
\begin{aligned}
{\left[A P C_{T}\right] } & =[A P C]+[A P C \mid C d h 1]+\left[A P C \mid C d c 20_{p}\right] \\
{[A P C \mid C d h 1] } & =k_{A P C}^{C d h 1} \cdot[C d h 1] \cdot[A P C] \\
{\left[A P C \mid C d c 20_{p}\right] } & =k_{A P C}^{C d c 20} \cdot\left[C d c 20_{p}\right] \cdot[A P C]
\end{aligned}
$$

Substituting the steady state values, we solve the equation for APC as 


$$
[A P C]=\frac{\left[A P C_{T}\right]}{1+k_{A P C}^{C d h 1} \cdot[C d h 1]+k_{A P C}^{C d c 20} \cdot\left[C d c 20_{p}\right]}
$$

\section{A.4 Cyclin B steady state}

Cyclin B exists in two forms in our model: $C y c B_{\text {act }}$ (active Cyclin B) and $C y c B_{\text {inact }}$ (inactive Cyclin B). Inactive Cyclin B equation is adapted from Pomerening et al. (2005) with the simplification that the phosphorylation/dephosphorylation of the three inactive forms of Cyclin B viz transcribed Cyclin B $(C y c B)$, Tyrosine phosphorylated $\left(C y c B^{Y}\right)$, and Tyrosine and Threonine phosphorylated $\left(C y c B^{Y T}\right)$ is fast enough to be always in equilibrium; so that equation for $C y c B^{Y T}$ can be algebraically solved.

$$
\begin{aligned}
{\left[C y c B_{\text {inact }}\right] } & =[C y c B]+\left[C y c B^{Y}\right]+\left[C y c B^{Y T}\right] \\
{[C y c B] } & =k_{2} \cdot \frac{\left[C d c 25_{p}\right]}{[W e e 1]} \cdot\left[C y c B^{Y}\right] \\
{\left[C y c B^{Y}\right] } & =k_{1} \cdot \frac{C y c B^{Y T}}{W e e 1} \\
{\left[C y c B^{Y T}\right] } & =\frac{C y c B_{\text {inact }} \cdot W e e 1^{2}}{W e e 1^{2}+k 1 \cdot W e e 1+k 1 \cdot k 2 \cdot C d c 25_{p}}
\end{aligned}
$$

\section{A.5 Mitosis}

$$
\begin{aligned}
\frac{d[C y c A]}{d t} & =v_{C A}^{E 2 F} \cdot E 2 F-d_{C A}^{C d h 1} \cdot[A P C \mid C d h 1] \cdot[C y c A] \\
& -d_{C A} \cdot[C y c A]-\frac{d[C y c A \mid C K I]}{d t} \\
\frac{d[C y c A \mid C K I]}{d t} & =v_{C A}^{C K I} \cdot[C y c A] \cdot[C K I]-d_{C A}^{C K I} \cdot[C y c A \mid C K I] \\
\frac{d\left[C y c B_{\text {inact }}\right]}{d t} & =v_{C B}^{E 2 F} \cdot E 2 F-k_{a 1} \cdot\left[C d c 25_{p}\right] \cdot\left[C y c B^{Y T}\right] \\
& +P_{C B}^{W e e 1} \cdot[W e e 1] \cdot\left[C y c B_{a c t}\right]-d_{C B}^{C d h 1} \cdot[A P C \mid C d h 1] \cdot\left[C y c B_{\text {inact }}\right] \\
& -d_{C B}^{C d c 20} \cdot\left[A P C \mid C d c 20_{p}\right] \cdot\left[C y c B_{\text {inact }}\right]-d_{C B} \cdot\left[C y c B_{\text {inact }}\right](\mathrm{A} .26) \\
\frac{d\left[C y c B_{a c t}^{T}\right]}{d t} & =-P_{C B}^{W e e 1} \cdot[W e e 1] \cdot\left[C y c B_{a c t}\right]+k_{a 1} \cdot\left[C d c 25_{p}\right] \cdot\left[C y c B^{Y T}\right] \\
& -d_{C B}^{C d h 1} \cdot[A P C \mid C d h 1] \cdot\left[C y c B_{a c t}\right] \\
& -d_{C B}^{C d c 20} \cdot\left[A P C \mid C d c 20_{p}\right] \cdot\left[C y c B_{a c t}\right]-d_{C B} \cdot\left[C y c B_{a c t}\right] \\
\frac{d[W e e 1]}{d t} & =W e e 1_{b}-P_{W e e 1}^{C B} \cdot\left[C y c B_{a c t}\right] \cdot[\text { Wee } 1]+P_{W e e 1}^{d e p h o s} \cdot\left[\text { Wee } 1_{p}\right] \\
& -d_{W e e 1} \cdot[\text { Wee1 }]
\end{aligned}
$$




$$
\begin{aligned}
\frac{d\left[W e e 1_{p}\right]}{d t} & =P_{W e e 1}^{C B} \cdot\left[C y c B_{a c t}\right] \cdot[W e e 1]-P_{W e e 1}^{d e p h o s} \cdot\left[\text { Wee } 1_{p}\right] \\
& -d_{W e e 1} \cdot[\text { Wee1 }] \\
\frac{d[C d c 25]}{d t} & =C d c 25_{b}-P_{C d c 25}^{C B} \cdot\left[C y c B_{a c t}\right] \cdot[C d c 25] \\
& +p_{C d c 25}^{d e p h o s} \cdot\left[C d c 25_{p}\right]-d_{C d c 25} \cdot[C d c 25] \\
\frac{d\left[C d c 25_{p}\right]}{d t} & =P_{C d c 25}^{C B} \cdot\left[C y c B_{a c t}\right] \cdot[C d c 25]-P_{C d c 25}^{d e p h o s} \cdot\left[C d c 25_{p}\right] \\
& -d_{C d c 25} \cdot\left[C d c 25_{p}\right] \\
\frac{d[C d h 1]}{d t} & =C d h 1_{b}-P_{C d h 1}^{C A} \cdot[C y c A] \cdot[C d h 1]-P_{C d h 1}^{C B} \cdot\left[C y c B_{a c t}\right] \cdot[C d h 1] \\
& +P_{C d h 1}^{d e p h o s} \cdot\left[C d h 1_{p}\right]-k_{C d h 1} \cdot[A P C] \cdot[C d h 1] \\
& -d_{C d h 1} \cdot[C d h 1] \\
\frac{d\left[C d h 1_{p}\right]}{d t} & =P_{C d h 1}^{C A} \cdot[C y c A] \cdot[C d h 1]+P_{C d h 1}^{C B} \cdot\left[C y c B_{a c t}\right] \cdot[C d h 1] \\
& -P_{C d h 1}^{d e p h o s} \cdot\left[C d h 1_{p}\right]-d_{C d h 1} \cdot\left[C d h 1_{p}\right] \\
\frac{d[C d c 20]}{d t} & =C d c 20_{b}-P_{C d c 20}^{C B} \cdot\left[C y c B_{a c t}\right] \cdot[C d c 20]+p_{C d c 20}^{d e p h o s} \cdot\left[C d c 20_{p}\right] \\
& -d_{C d c 20}^{C d h 1} \cdot[A P C \mid C d h 1] \cdot[C d c 20]-d_{C d c 20} \cdot[C d c 20] \\
\frac{d\left[C d c 20_{p}\right]}{d t} & =P_{C d c 20}^{C B} \cdot\left[C y c B_{a c t}\right] \cdot[C d c 20]-P_{C d c 20}^{d e p h o s} \cdot\left[C d c 20_{p}\right] \\
& -d_{C d c 20}^{C d h 1} \cdot[A P C \mid C d h 1] \cdot\left[C d c 20_{p}\right]-k_{C d c 20} \cdot[A P C] \cdot\left[c d c 20_{p}\right] \\
& -d_{C d c 20} \cdot\left[C d c 20_{p}\right]
\end{aligned}
$$

\section{A.6 Wee1 gated circadian regulation}

$$
\begin{aligned}
\frac{d[\text { Wee } 1]}{d t} & =W e e 1_{c} \cdot(1+\sin (2 \pi / 24 \cdot(t-6))) \\
& -P_{\text {Wee } 1}^{C B} \cdot\left[\text { CycB } B_{a c t}\right] \cdot[\text { Wee } 1]+P_{\text {Wee } 1}^{\text {dephos }} \cdot\left[\text { Wee } 1_{p}\right] \\
& -d_{W e e 1} \cdot[\text { Wee } 1]
\end{aligned}
$$

\section{A.7 HGF injection}

$$
\begin{aligned}
d[H G F] & =\frac{V_{H G F}^{I E G} \cdot[I E G]}{1+\left(\frac{[P A I]}{K m_{H G I}^{P A I} 4}\right)} \cdot\left(1+\frac{f \cdot[H G F]}{K m_{H G F}^{I E G}+[H G F]}\right) \\
& -d_{H G F} \cdot[H G F]+h g f s \cdot(t<40) \cdot(t>36)
\end{aligned}
$$




\section{B Parameters}

\begin{tabular}{|c|c|c|c|c|c|}
\hline $\mathbf{G}_{1}-\mathbf{S}$ & & $d_{11} 6$ & $v_{C A}^{C K I} 0.01$ & & \\
\hline$I_{0} 4$ & $v_{6} 15$ & $v_{12} 0.56$ & $d_{C A}^{C K I} 0.1$ & & \\
\hline$d_{0} 0.05$ & $k_{61} 0.9$ & $d_{12} 0.025$ & $k_{1} 0.03$ & $P C A \quad 0 ?$ & \\
\hline$v_{1} 1.5$ & $k_{62} 0.0005$ & $d_{122} 0.75$ & $k_{2} 5$ & $\begin{array}{l}{ }_{C d h 1} 0.2 \\
P_{C B}^{C B}\end{array}$ & \\
\hline$k_{1}^{-} \quad 0.9$ & $k_{63} 1.0$ & E2F & $k_{a 1} 60$ & $\begin{aligned} P_{C d h 1} 0.01 \\
P^{\text {dephos }} 001\end{aligned}$ & \\
\hline$k_{1} 0.5$ & $d_{6} 0.05$ & $E 2 F_{T} 0.05$ & $v_{C B}^{E 2 F} 1.2$ & $\begin{array}{l}P_{C d h 1} \\
P^{2}\end{array}$ & \\
\hline$d_{1} 0.5$ & $v_{7} 8$ & $R b_{T} 1$ & $d_{C B} 0.01$ & 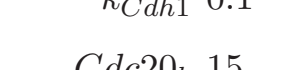 & Bifurcation F2F \\
\hline$v_{2} 0.6$ & $d_{7} 8$ & $p 13$ & $d_{C B}^{C d h 1} 0.8$ & $d_{C d c 0} 0.005$ & D 4 \\
\hline$d_{2} 0.006$ & $v_{8} 3$ & $p_{2} 4$ & $d_{C B}^{C d c 20} 0.2$ & $d_{C d h 1}^{C} 20$ & \\
\hline$v_{3} 4.5$ & $k_{8} 0.001$ & $k_{1} 25$ & $P_{C B}^{W e e 1} 8$ & $\begin{array}{ll}{ }^{l} C d c 20 \\
P_{C B}^{C B} 10\end{array}$ & D 4 \\
\hline$k_{3} 0.7$ & $d_{8} 0.03$ & $k_{2} 1$ & $W e e 1_{b} 1$ & $P_{C}^{\text {dephos }} 0.01$ & $E 2 F 0.5$ \\
\hline$d_{3} 6$ & $v_{91} 5$ & $\begin{array}{ll}k_{3} & 0.1 \\
& \end{array}$ & $d_{W e e 1} 0.5$ & $k_{C d c 20} 0.1$ & \\
\hline$v_{4} 45$ & $k_{91} 30$ & $\mathrm{APC}$ & $P_{W e e 1}^{C B} 3$ & HGFinjection & \\
\hline $\begin{array}{lll}k_{4} & 0.5\end{array}$ & $v_{92} 5$ & $A P C_{T} 1$ & $P_{\text {Wee1 }}^{\text {dephos }} 0.02$ & hgfs 0.4 & \\
\hline 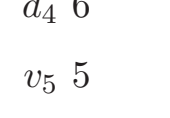 & $\begin{array}{ll}k_{92} & 30 \\
d_{9} & 0.01\end{array}$ & $\begin{array}{ll}k_{A P C} & 0.5 \\
k_{A P C}^{C d c 20} & 0.1 \\
\end{array}$ & $d_{C d c 25} 0.2$ & Wee1 - gated & \\
\hline$f_{5} 5$ & $v_{10} 0.008$ & Mitosis & $P_{C d c 25}^{C B} 5$ & Weet $1_{c} 1.5$ & \\
\hline$k_{5} 0.25$ & $d_{10} 0.0008$ & $v_{C A}^{E 2 F} 1.75$ & $P_{C d c 25}^{d e p h o s} 0.3$ & $20 S_{C d c 25} \quad 0.3$ & \\
\hline$k_{5}^{-} 0.18$ & $v_{11} 2$ & $d_{C A}^{C d h 1} 1$ & $C d h 1_{b} 0.2$ & & \\
\hline$d_{5} 0.05$ & & $d_{C A} 0.1$ & $d_{C d h 1} 0.1$ & & \\
\hline
\end{tabular}




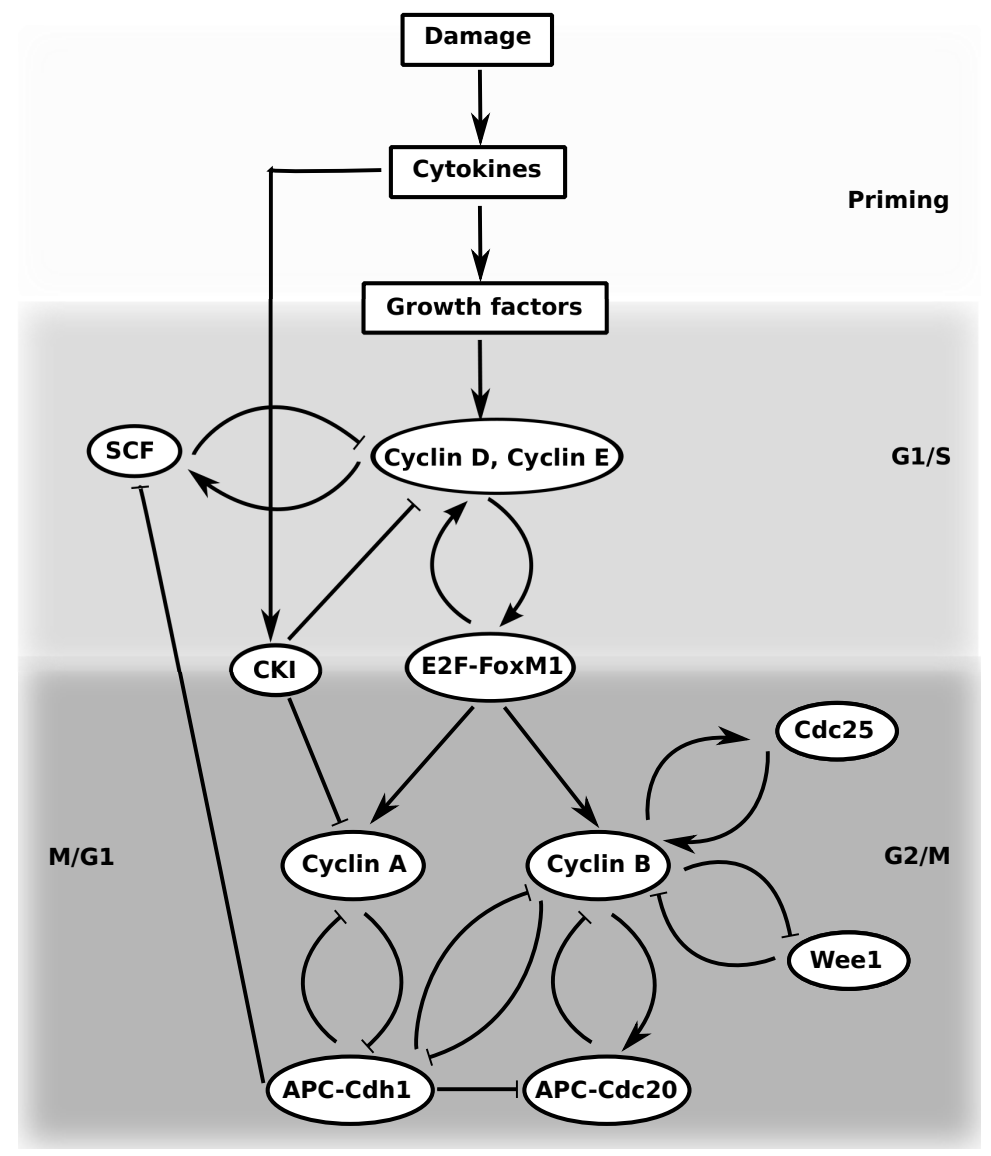

Fig. 1. Damage induced model of the cell cycle during liver regeneration based on sequential cyclin activation and degradation. The PH-induced damage primes quiescent cells via cytokine signaling. Primed cells then activate growth factor-induced signaling cascades. Cytokine- and growth factor-induced pathways act in concert to provide mitogenic signals for Cyclin D activation in early G1 phase. Cyclin D initiates a chain of sequential phosphorylation of $\mathrm{Rb} / \mathrm{E} 2 \mathrm{~F}$ which leads to sequential transcription of further G1-S (Cyclin E), S (Cyclin A) and M (Cyclin B) phase cyclins. As early as G1 phase, stoichiometric inhibitors of cyclins, CKI, are also activated by cytokines. The G1-S proteolytic degradation machinery, SCF, is activated by Cyclin E. Entry to mitosis is initiated by the abrupt activation of Cyclin B by Cdc25 and Wee1 in a positive feedback loop fashion at G2-M transition. Cdc25and Wee1-mediated positive feedback loops also regulate the rapid exit from mitosis by swiftly inactivating Cyclin B at M-G1 in coordination with a positive feedback loop from the M-G1 degradator $\mathrm{APC}^{C d h 1}$. Mitotic degradator $\mathrm{APC}^{C d c 20}$ exerts a negative feedback loop. All cyclin-cdk complexes are depicted by their respective activating cyclin partner for simplicity. E2F in the scheme represents all three forms of E2F, viz, unphosphorylated, hypophosphorylated and hyperphosphorylated 

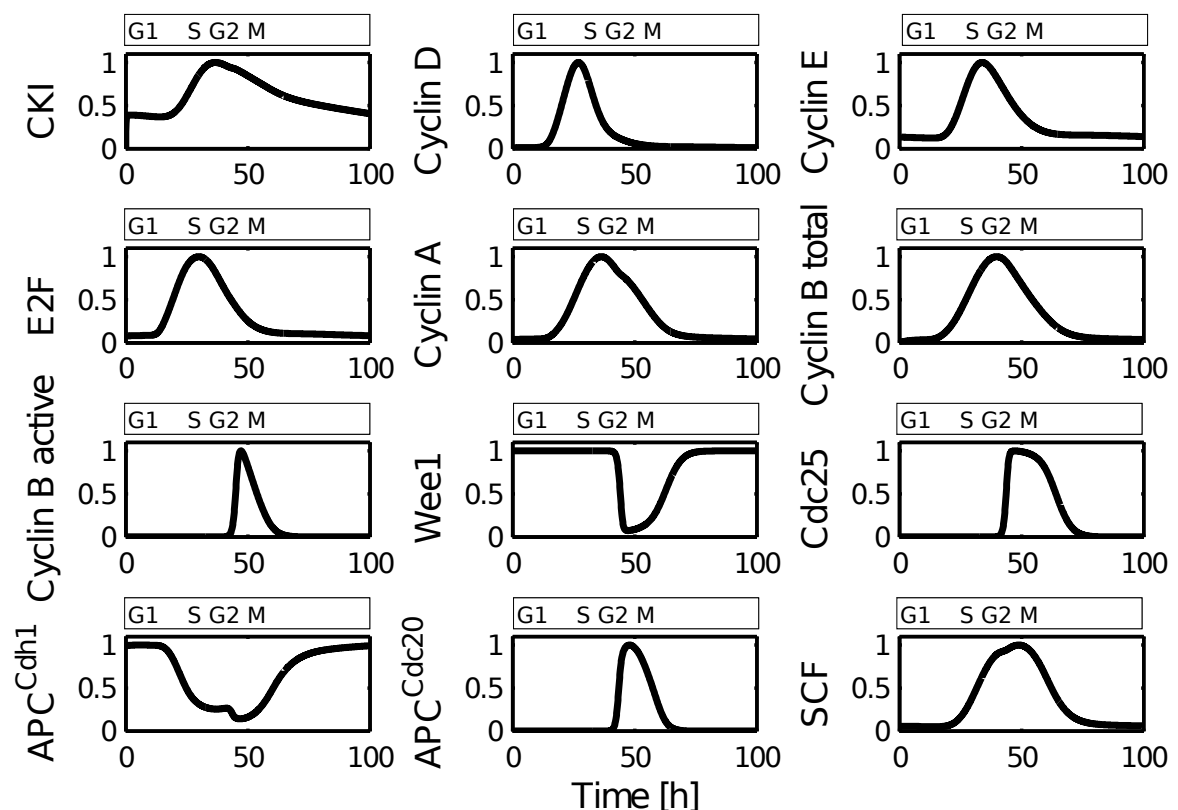

Fig. 2. Sequential activation and degradation of cyclins and their key regulators. Cyclin D appears at the late G1, Cyclin E at the G1-S transition, Cyclin A in the $\mathrm{S}$ phase and Cyclin $\mathrm{B}$ in the late $\mathrm{S}$ phase and mitosis. At the G2-M interface, transient activation of Cyclin B active, Cdc25 and inactivation of Wee1, leads to abrupt mitotic entry. At the M-G1 interface, Cdc25 and Wee1 are respectively rapidly inactivated and activated, leading to swift exit from mitosis. APC $\mathrm{Adc}^{20}$ is also transiently activated once enough Cyclin B has accumulated at mitosis. $\mathrm{APC}^{C d h 1}$ is active from late mitosis to G1 phase keeping Cyclin A and Cyclin B degraded in a positive feedback loop fashion during late mitosis and G1. SCF is activated by Cyclin E during G1-S phase leading to degradation of G1-S cyclins. All concentrations are normalized by their maximum concentrations. 

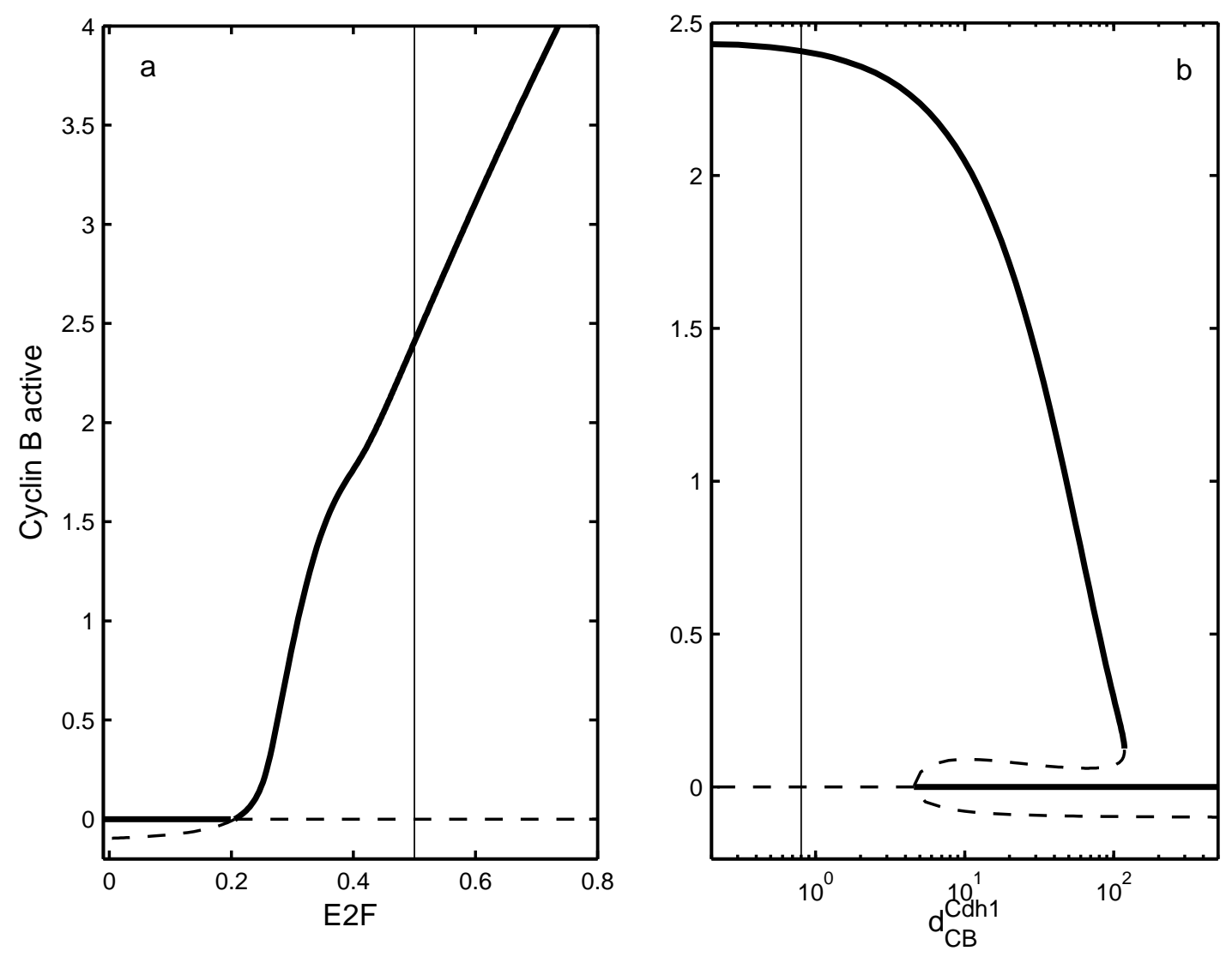

Fig. 3. Threshold activation of Cyclin B driving M phase progression. (a) Bifurcation diagram with respect to E2F activity. Steady states in Cyclin B activity are plotted as a function of E2F activity. At any E2F level, Cyclin B activity has two steady states, one zero and one either negative or positive. The two steady states exchange their stability when they meet. The largest (zero or positive) steady state is always stable and the smallest always unstable. (b) Bifurcation diagram with respect to the degradation rate $\mathrm{d}_{C B}^{C d h 1}$. Steady states in Cyclin B activity are plotted as a function of the degradation rate $\mathrm{d}_{C B}^{C d h 1}$. Over a large range of degradation rates, Cyclin $\mathrm{B}$ activity has two stable steady states. In a and b, thick solid lines represent stable steady states and dashed lines, unstable steady states. The vertical lines represent the set values of $\mathrm{E} 2 \mathrm{~F}$ and $d_{C B}^{C d h 1}$ for the bifurcation diagrams for $d_{C B}^{C d h 1}$ and $\mathrm{E} 2 \mathrm{~F}$ respectively. 


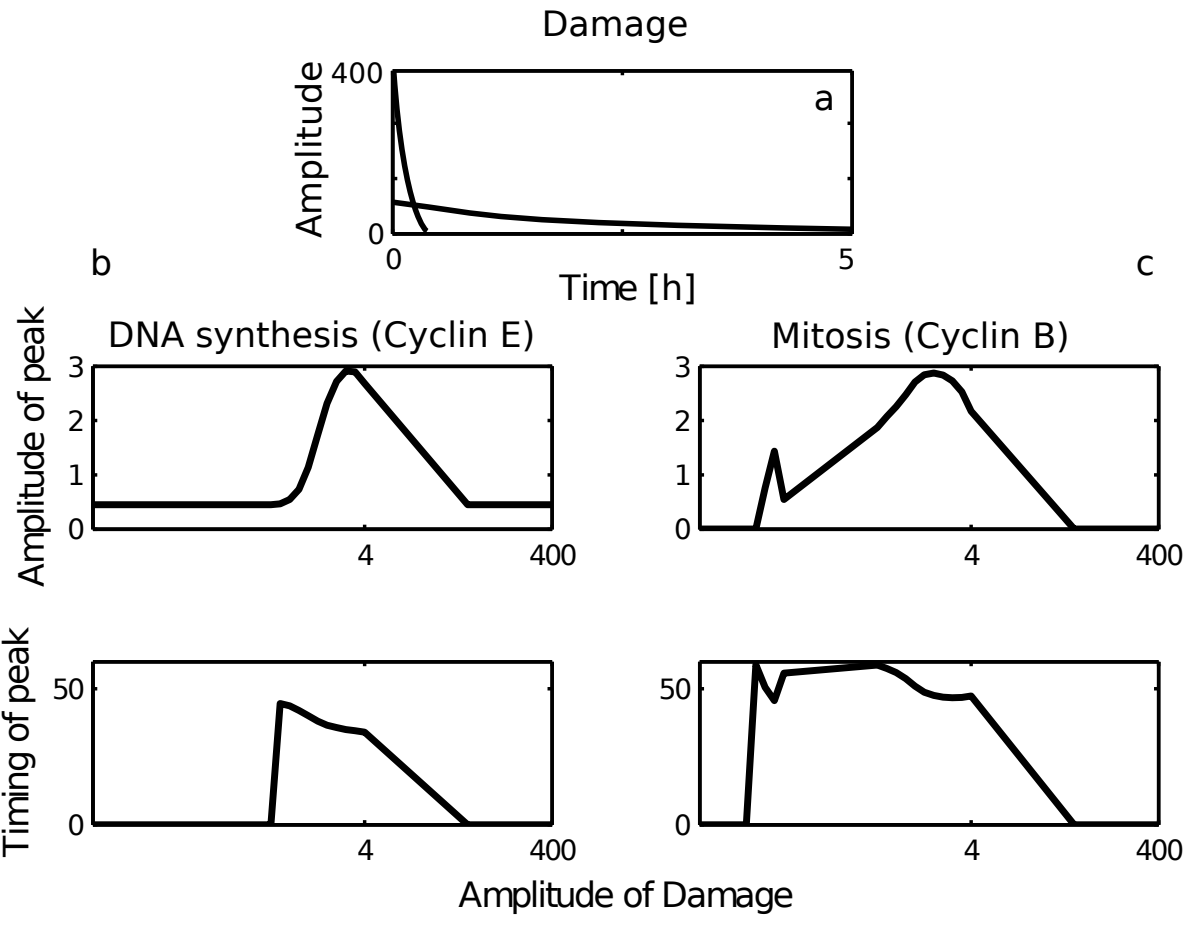

Fig. 4. Bandpass filter characteristics of the model. Both DNA synthesis (Cyclin E) (b, top) and mitosis (Cyclin B) (c, top) exhibit bandpass filtering properties when the damage (a) is changed systematically from weak-sustained damage to strong-transient damage, keeping the total amount of damage constant. Timing remains relatively constant (b and c, bottom). 

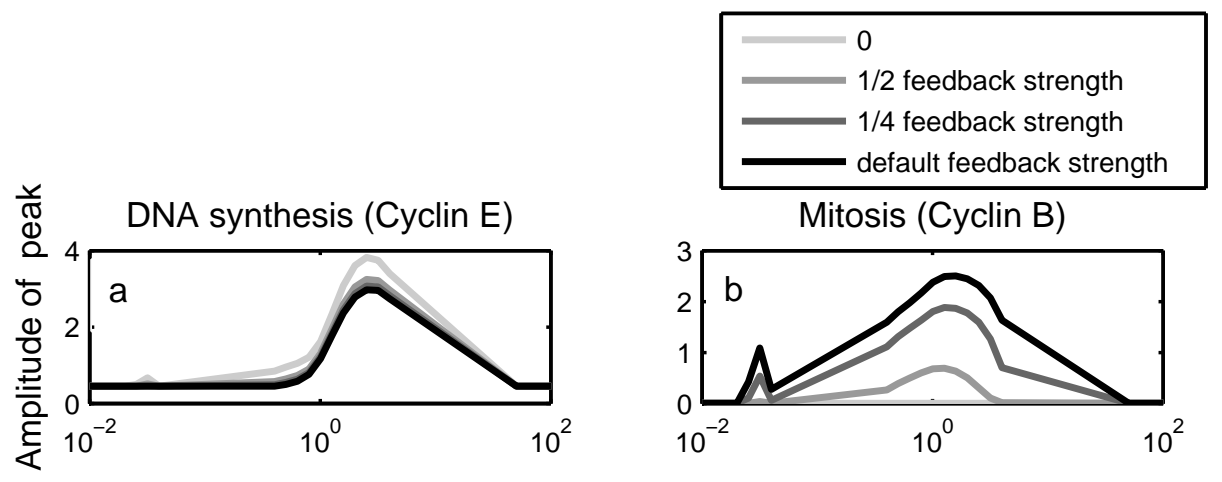

Fig. 5. Opposite bandpass filtering effect on DNA synthesis (a) and mitosis (b) with respect to changing feedback strength of Cdh1-Cyclin A loop.
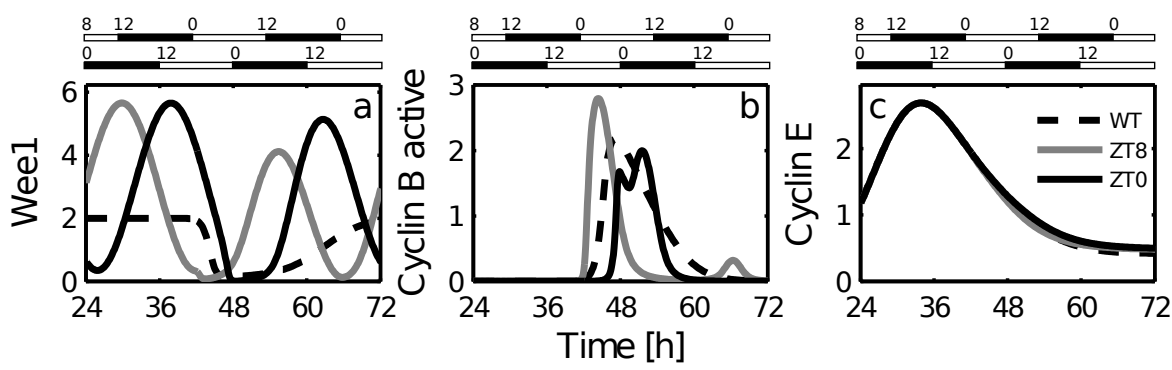

Fig. 6. Cyclin B (a) and Wee1 (b) activity in response to PH performed at different times of the day (ZT8 represents 8 hours after light is on; ZT0 represents 0 hour after light is on, in a $12 \mathrm{~h}$ light-dark cycle). In ZT8 mice, Wee1 peaks 8 hours earlier than in ZT0 mice; that leads to a 7.5 hour-advanced peak of Cyclin B activity. Cyclin E (c) shows no change in activity between ZT0 and ZT8. 

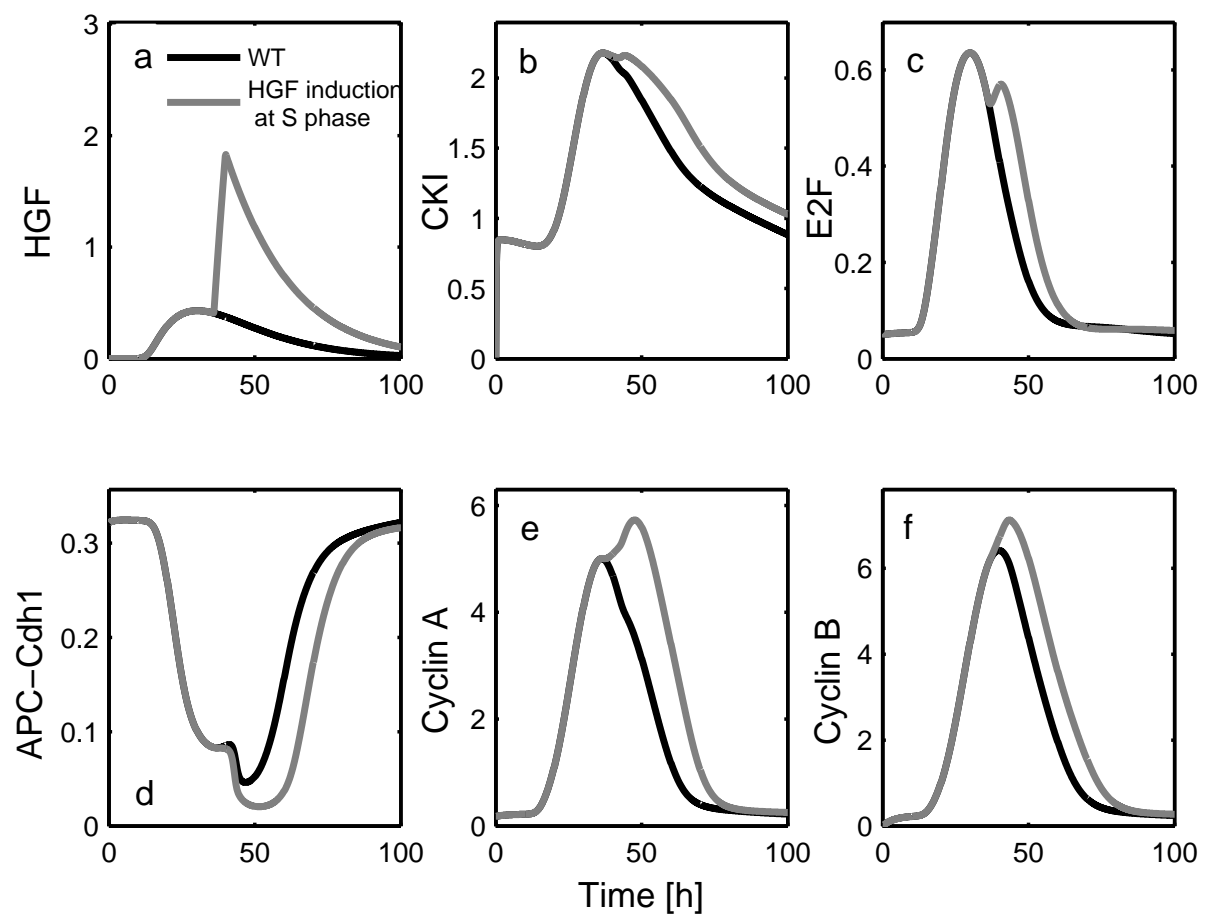

Fig. 7. Growth factor induction at $\mathrm{S}$ phase delays $\mathrm{G} 2$ phase. Induction of HGF at Spahse (a) leads to delay in the degradation of Cyclin A (e) and Cyclin B (f). CKI (b), E2F (c) and $\mathrm{APC}^{C d h 1}$ (d) contribute together in causing this delayed degradation of G2-M cyclins. 